population. These cells have distinct origins and phenotype from both tissue resident macrophages and circulating non-classical monocytes. Further, the findings presented here strongly suggest intravascular are a key effector cells in inflammatory arthritis.

Disclosure of Interests: None declared

DOI: 10.1136/annrheumdis-2019-eular.8320

\section{SAT0107 BIOMARKERS OF CLINICAL RELAPSE AND RADIOLOGICAL PROGRESSION IN PATIENTS WITH RHEUMATOID ARTHRITISIN REMISSION. OBSERVATIONAL STUDY OF 5 YEARS OF FOLLOW-UP}

Julio Ramirez ${ }^{1}$, Andrea Cuervo ${ }^{1}$, Raquel Celis ${ }^{1}$, Raul Castellanos-Moreira ${ }^{2}$, Sebastian C. Rodriguez-García ${ }^{3}$, Virginia Ruiz-Esquide ${ }^{3}$, José Gomez Puerta ${ }^{3}$ Raimón Sanmartí1, Juan D. Cañete ${ }^{1}{ }^{1}$ Hospital Clinic de Barcelona, Barcelona, Spain; ${ }^{2}$ Hospital Clínic, BArcelona, Spain; ${ }^{3}$ Hospital Clínic, Barcelona, Spain

Background: Patients with Rheumatoid Arthritis (RA) in remission will present flares during the evolution of the disease.Definitive biomarkers have not been identified to predict flares and radiographic progression (RP) in this kind of patients

Objectives: To search biomarkers of clinical relapse and RP in patients with RA in clinical remission

Methods: RA patients in clinical remission (DAS28-ESR<2.6 for $>6$ months) were selected.Clinical,epidemiological and serological data were analyzed. MRI of dominant hand,ultrasound assessment of knees and hands and serum levels of inflammation and angiogenesis biomarkers were evaluated at 0 and 48 weeks.Synovial biopsy was performed in patients with subclinical synovitis.Patients were follow-up for 5 years.Radiological data were collected.Clinical relapse was defined as the loss of remission status involving a therapeutic intervention.RP was defined as the change in the Sharp van der Heijde $(\mathrm{SvH})$ index at 5 years $>10.47$ [SDD (minimum detectable change)]

Results: 60 patients in DAS28 remission. $1 / 3$ also met remission criteria for $\operatorname{SDAl}(33.3 \%), \operatorname{CDAl}(31.6 \%)$ and $\operatorname{ACR}(35 \%) .78 \%$ were women, mean age 53 years. $82 \%$ were ACPA+. $26 \%$ were taking oral prednisone, $76 \%$ DMARDs and $45 \%$ biological therapies. $48 \%$ met criteria for subclinical synovitis(UdAS:SH>2+PD) ${ }^{1}$.

After 5 years of follow-up, 44(73\%), 11(18\%), 9(15\%) and 10(17\%) patients remained in remission according to DAS28,SDAI, DAI and ACR criteria,respectively.

29 patients $(48 \%)$ had flares at any time during the 5 years. In the multivariate analysis, the variables that were related to clinical relapse were the $\mathrm{BMI}$ (OR $1.6 \mathrm{Cl} 95 \%$ 1.1-2.3), bone edema at baseline (OR 1.2, Cl $95 \% 1-1.5$ ), PD signal at $48 \mathrm{w}$ (OR $9.2, \mathrm{Cl} 95 \% 1.2-66.7$ ) and the change in levels of CXCL16 (OR $1.04 \mathrm{Cl} 95 \%$ 0.9-1) and ESR (OR 3.6,Cl 95\% 1.1-12.2) between the first and latest evaluation (Rate). In the subgroup of 23 patients undergoing synovial biopsy, the number of mast cells was higher in those patients $(n=10)$ who flared $(p=0.02)$.

20 patients $(33 \%)$ changed DMARDs or biological therapy. In the logistic regression analysis, BMI (OR $1.3 \mathrm{Cl} 95 \%$ 1-1.6), biological therapy (OR $17.8 \mathrm{Cl} 95 \%$ 2-167.1),progression of erosions measured by MRI (OR 1.1, $\mathrm{Cl} 95 \% 1-1.3)$ and the rate of progression of calprotectin levels during the first year (OR 4.4, $\mathrm{Cl} 95 \%$ 1.1-17.2) were the main factors that predicted the change in baseline therapy after 5 years of follow-up.

Finally, only 6 patients $(10 \%)$ had RP according to the SvH index and 7 $(12 \%)$ had erosion progression. This small number of "progressors" did not allowed more exhaustive analysis of factors predicting RP. However,the number of macrophages and T cells at sinovial tissue (ST) was much higher in patients with RP.Likewise,the first-year rate of bone edema was significantly higher in patients suffering structural progression $(p=0.04)$.

Conclusion: $27 \%$ of RA patients lost clinical remission (DAS28) after 5 years of follow-up.BMI,baseline bone edema,PD signal at $12 \mathrm{~m}$ and firstyear rate of CXCL16 and VSG levels were predictors of joint flares. Baseline BMI, use of biological therapy,MRI erosions and calprotectin levels predicted the change of baseline therapy for RA. Only $10 \%$ of patients had RP along the study.Sinovial mast cells were associated with disease flares. Macrophages and T cells in ST were higher in patients with RP in an exploratory analysis.

\section{REFERENCE}

[1] Ramirez J, Ruiz-Esquide V, Pomes I, Celis R, Cuervo A, Hernandez MV, et al. Patients with rheumatoid arthritis in clinical remission and ultrasounddefined active synovitis exhibit higher disease activity and increased serum levels of angiogenic biomarkers. Arthritis Res Ther. 2014;16:R5
Disclosure of Interests: Julio Ramirez: None declared, Andrea Cuervo: None declared, Raquel Celis: None declared, Raul Castellanos-Moreira Speakers bureau: MSD, Lilly, Sebastian C Rodriguez-García: None declared, Virginia Ruiz-Esquide: None declared, José Gomez Puerta Speakers bureau: BMS, Pfizer, Amgen, Raimón Sanmartí Speakers bureau: PFIZER, SANOFI, LILLY, MSD, UCB, NOVARTIS, JANSSEN, Juan D. Cañete: None declared

DOI: 10.1136/annrheumdis-2019-eular.7169

\section{SAT0108 1 CHARACTERISTICS OF MULTIRESISTANT PATIENTS TO BIOLOGICAL TREATMENTS IN RHEUMATOID ARTHRITIS, AND ASSOCIATED FACTORS : AN OBSERVATIONAL AND RETROSPECTIVE STUDY IN 385 PATIENTS}

Laetitia Richard $^{1,2}$, Henri Gonde ${ }^{3}$, Agathe Devauchelle ${ }^{1}$, Pascal Rottenberg ${ }^{1}$ Gilles Avenel ${ }^{1}$, Macha Kozyreff-Meurice ${ }^{1}$, Sophie Pouplin ${ }^{1}$, Olivier Vittecoq ${ }^{1}$, Thierry Lequerre ${ }^{1} .{ }^{1}$ Rouen University Hospital, Rheumatology, ROUEN, France; 2 Jacques Monod Hospital Center, Rheumatology, MONTIVILLIERS, France; ${ }^{3}$ Rouen University Hospital, Pharmacy, ROUEN, France

Background: Despite a wide range of biological treatments (bDMARDs) in the management of rheumatoid arthritis (RA), some patients fail in different lines of treatment. Currently, there is no consensual definition of multiresistance to bDMARDs in RA.

Objectives: The aim of our study was to describe the characteristics of " multiresistant » patients and to establish associated factors with multiresistance to bDMARDs in RA.

Methods: In this observational and retrospective study were identified patients with RA admitted for administration of a bDMARD at Rouen University Hospital (France) between January 2007 and July 2017 (sources diagnostic coding using International Classification of Diseases 10th revision and traceability of intra-hospital pharmacy). In the absence of a consensual definition, multiresistance to bDMARD was defined in this study by failure, primary and/or secondary, to at least 2 bDMARDs. The clinical and paraclinical characteristics of these patients at the initiation of the first bDMARD were collected using data from their standardized monitoring, then compared to those of patients who received a single bDMARD effective for 10 years or more, constituting the "responder" group.

Results: We identified 794 patients: 385 constituted our active RA file under bDMARD, 192 patients excluded for different reasons (6 patients not fulfilling the ACR/EULAR 2010 criteria, 18 followed in another department, 45 for missing data at bDMARD's initiation, 50 not found in com puterized file, 73 for whom the expected bDMARD was never started) and 217 lost to follow-up. Among our active RA file under bDMARD (385 patients), 53 were « multiresistant » (at least 2 bDMARDs failed), and 50 patients received a single and effective bDMARD for 10 years or more, after excluding some patients for missing data (Figure 1). The mean age of « multiresistant » patients at initiation of bDMARD was 50.3 years $( \pm 13.2$ years), and the sex ratio was 2.8 women $/ 1$ man. They presented erosive RA $(77.4 \%)$, rheumatoid factor and anti-citrullinated peptide antibodies positive $(73.6 \%)$, highly active (median number of tender and swollen joints $8 / 28$, median visual analog scale disease activity $70 /$ 100, median C-reactive protein (CRP) $21 \mathrm{mg} / \mathrm{L}$, mean Disease Activity Score 28 CRP mean 5.36 \pm 1.28 ), and with high functional impact (Health Questionnaire Median Assessment: 1,500/3). The age of disease onset was significantly later in " multiresistant » patients than in " responder " patients $(43 \pm 14.2$ years versus $37.9 \pm 10.7$ years, $p=0.042)$. No demographic, anamnestic, clinical and paraclinical characteristics differed significantly between « multiresistant » and « responder » patients.

Conclusion: It is an original work, counting in the literature as a single similar study [1], with nevertheless significant methodological differences. There is no consensual definition of multiresistance to bDMARD in RA and its mechanisms remain misunderstood. Identifying predictive factors would make it possible to early identified patients with a refractory profile in order to adapt the therapeutic strategy. Multidrug resistance in RA remains one of the challenges in the management of this pathology.

\section{REFERENCE}

[1] Kearsley-Fleet L, Davies R, De Cock D, Watson KD, Lunt M, Buch MH, et al. Biologic refractory disease in rheumatoid arthritis: results from the British Society for Rheumatology Biologics Register for Rheumatoid Arthritis Ann Rheum Dis Epub ahead of print : 8 July 2018 


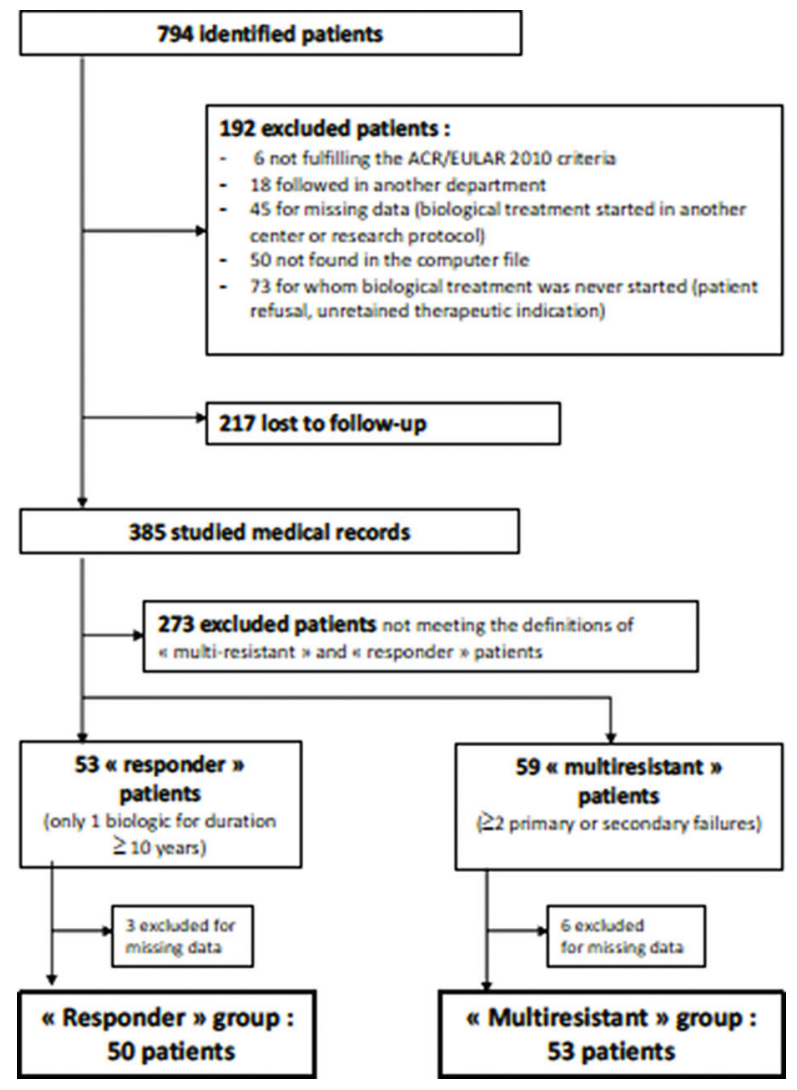

Disclosure of Interests: None declared

DOI: 10.1136/annrheumdis-2019-eular.1646

\section{SAT0109 SMOKING CESSATION IN PATIENTS WITH RA IS ASSOCIATED WITH REDUCED CVD EVENT RATES AND IMPROVED LIPID PROFILES AND PREDICTS LOWER RA DISEASE ACTIVITY}

Ida Kristiane Roelsgaard ${ }^{1}$, Eirik Ikdahl ${ }^{2}$, Silvia Rollefstad ${ }^{2}$, Grunde Wibetoe ${ }^{2}$, Bente Appel Esbensen ${ }^{1}$, George D. Kitas ${ }^{3,4}$, Piet van Riel ${ }^{5}$, Sherine Gabriel ${ }^{6}$, Tore K. Kvien ${ }^{7}$, Karen Douglas ${ }^{8}$, Solveig Wallberg Jonsson ${ }^{9}$, Solbritt Rantapaa Dahlqvist ${ }^{9}$, George Karpouzas ${ }^{10}$, Patrick Dessein ${ }^{11,12}$, Linda Tsang ${ }^{12}$, Hani El-Gabalawy ${ }^{13}$, Carol Hitchon ${ }^{13}$, Virginia Dr. Pascual ${ }^{14}$, Irazu ContrerasYáñez $^{14}$, Petros Sfikakis ${ }^{15}$, Miguel A. González-Gay ${ }^{16}$, Cynthia S. Crowson ${ }^{6}$, Anne Grete Semb ${ }^{2} .{ }^{1}$ Rigshospitalet, Center for Rheumatology and Spine Diseases, Copenhagen Center for Arthritis Research (COPECARE), Glostrup, Denmark; ${ }^{2}$ Diakonhjemmet Hospital, Preventive Cardio-Rheuma Clinic, Department of Rheumatology, Oslo, Norway, ${ }^{3}$ Dudley Group NHS Foundation Trust, West Midlands, United Kingdom ${ }^{4}$ University of Birmingham, School of Sport, Exercise and Rehabilitation, Birmingham, United Kingdom ${ }^{5}$ Radboud University Medical Center, Radboud Institute for Health Sciences, IQ healthcare, Nijmegen, Netherlands; ${ }^{6}$ Mayo Clinic, Department of Medicine, Division of Rheumatology, Rochester, MN, United States of America; ${ }^{7}$ Diakonhjemmet Hospital, Department of Rheumatology, Oslo, Norway, ${ }^{8}$ Dudley Group NHS Foundation Trust, West Midlands, United Kingdom ${ }^{9}$ Umeå University, Department of Public Health and Clinical Medicine, Rheumatology, Umeå, Sweden; ${ }^{10}$ Division of Rheumatology, Harbor-UCLA Medical Center, Torrance, CA, United States of America; ${ }^{11}$ Vrije Universiteit Brussel, Brussel, Belgium; ${ }^{12}$ Universitair Ziekenhuis Brussel, Brussel, Belgium; ${ }^{13}$ University of Manitoba, Winnipeg, MB, Canada; ${ }^{14}$ Instituto Nactional de Ciencias Médicas y Nutrición Salvador Zubirán, México City, Mexico; ${ }^{15}$ National and Kapodistrian University of Athens, First Department of Propedeutic Internal Medicine, Athens, Greece; ${ }^{16}$ Rheumatology, Hospital Universitario Marqués de Valdecilla, IDIVAL, Universidad de Cantabria, Santander, Spain

Background: Smoking is a major risk factor for development of both cardiovascular disease (CVD) and rheumatoid arthritis (RA) and causes an attenuated response to antirheumatic treatment.

Objectives: The aim of this study was to compare disease activity and CVD risk factors across smoking status in RA patients. Further to evaluate the impact of smoking cessation on risk of future CVD events in these patients.

Methods: RA disease characteristics, CVD risk factors and relevant medication were recorded in patients from 10 countries (Norway, UK,
Netherlands, USA, Sweden, Greece, South Africa, Spain, Canada and Mexico). Information on CVD events were collected after a median followup of 3.54 years (inter-quartile range $2.51-6.06$ ). Adjusted analysis of variance, logistic regression and COX proportional hazards analyses with time to event as response variable were applied to compare RA disease activity (measured by DAS28), CVD risk factors and CVD event rates across current, former and never smokers.

Results: Among the 3311 included RA patients (1012 former, 887 current and 1412 never smokers), 235 experienced a CVD event(s) during follow-up. At enrollment into the study current smokers were more likely to have moderate/high disease activity compared to former and never smokers $(p<0.001$ for both) (Figure 1). There was a gradient of worsening CVD risk factor profiles (lipoproteins and blood pressure) from never smokers, via former smokers, to current smokers. Furthermore, after 3.54 years of follow up former and never smokers had significantly lower CVD event rates compared to current smokers (hazard ratio $(95 \%$ confidence interval): 0.70 (0.51, 0.95), $\mathrm{p}=0.02$ and $0.48, \quad(0.34,0.69), \quad \mathrm{p}<0.001$ respectively) (figure 2). The CVD event rates for former and never smokers were comparable.

Conclusion: We show for the first time that smoking cessation in RA patients was associated with lower disease activity, improved lipid profiles and was a predictor of reduced rates of CVD events.

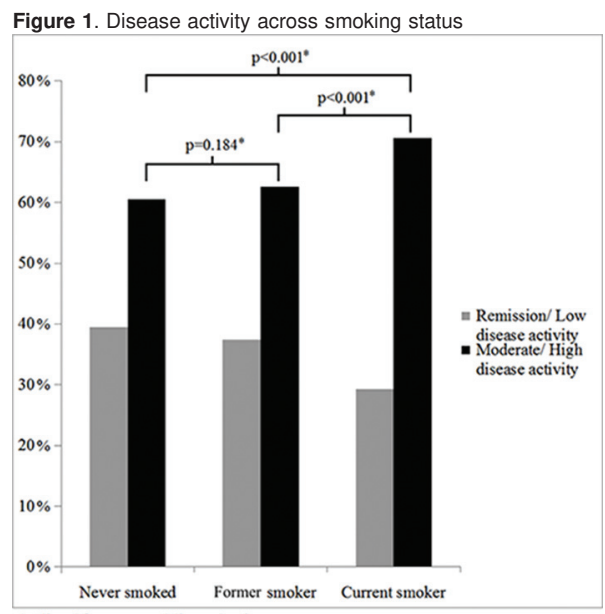

- Adjusted for age, sex and disease duration

Figure 2. Risk of future CVD event across smoking status in RA patients

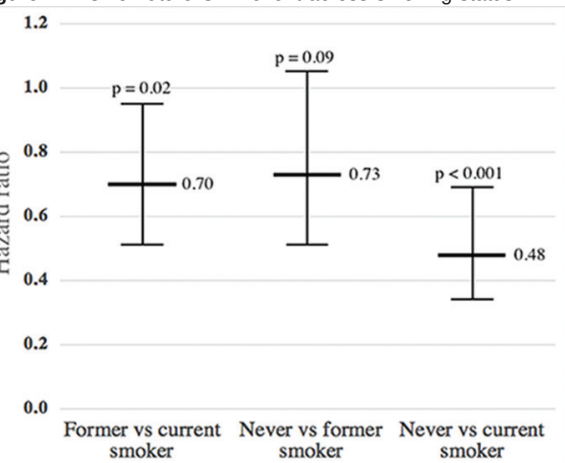

COX proportional hazards regression model adjusted for age, sex, statin and antihypertensive use. HR; hazard ratio, 95\% Cl: $95 \%$ confidence interval.

Disclosure of Interests: Ida Kristiane Roelsgaard: None declared, Eirik Ikdahl: None declared, Silvia Rollefstad: None declared, Grunde Wibetoe: None declared, Bente Appel Esbensen Speakers bureau: For Pfizer, George D Kitas Speakers bureau: GDK has received honoraria for lectures, participation in advisory boards and/or hospitality by Roche, Abbvie, Pfizer, Novartis, UCB, BMS, GSK and received grant support from Lilly., Piet van Riel: None declared, Sherine Gabriel: None declared, Tore K. Kvien Grant/research support from: AbbVie, BMS, MSD, Pfizer, Roche and UCB., Consultant for: AbbVie, Biogen, BMS, Boehringer Ingelheim, Celgene, Celltrion, Eli Lilly, Hospira, Merck-Serono, MSD, Novartis, Oktal, Orion Pharma, Pfizer, Roche, Sandoz, Sanofi, Mylan and UCB, Speakers bureau: AbbVie, Biogen, BMS, Boehringer Ingelheim, Celgene, Celltrion, Eli Lilly, Hospira, Merck-Serono, MSD, Novartis, Oktal, Orion Pharma, Pfizer, Roche, Sandoz, Sanofi and UCB, Karen Douglas: None declared, 